\title{
Energy transduction analyses of piezoelectric based vibration control of smart structures
}

\author{
$\begin{array}{lll}\text { J. L. Cao* } & \text { S. John* } & \text { T. Molyneaux }\end{array}$
}

(Received 22 May 2006; revised 21 April 2007)

\begin{abstract}
Passive vibration shunt control using piezoelectric materials and an electrical network can remove vibration energy from structures. However, the vibration shunt control efficiency relies on the optimization of the vibration energy transfer between a structure and a Lead-Zirconate-Titanate piezoelectric ceramic material. We present an analytical study of a parallel resistor-inductor piezoelectric vibration shunt control on a beam structure using Hamilton's principle and Galerkin's method. The influence of the material's mechanical property on vibration energy transfer between the structure and the LeadZirconate-Titanate is discussed. The results of the vibration shunt control with various materials obtained from numerical modeling and experiments are discussed and corroborated.
\end{abstract}

${ }^{*}$ School of Aerospace, Mechanical \& Manufacturing Engineering, RMIT University Bundoora East Campus, Melbourne, Australia. mailto:sabu.john@rmit.edu.au

${ }^{\dagger}$ School of Civil \& Chemical Engineering, RMIT University City Campus, Melbourne, AUstralia. mailto:tom.molyneaux@rmit. edu.au

See http://anziamj .austms.org.au/V47EMAC2005/Cao for this article, (c) Austral. Mathematical Soc. 2007. Published June 26, 2007. ISSN 1446-8735 


\section{Introduction}

Structural vibration control has been a subject of engineering research for the past few decades. Recently, the use of "smart" materials for vibration control has become an alternative to traditional vibration control techniques. Vibration control with smart materials has several advantages such as lighter weight, smaller size, flexibility in the structure and lower cost. They are especially suitable where the traditional techniques cannot be applied due to weight and size restrictions.

The smart material components such as Lead-Zirconate-Titanate (PZT), a piezoelectric ceramic material, converts mechanical energy into electrical energy and vice versa. Hagood and von Flotow [3] demonstrated that the vibrations of the structure can be damped with piezoelectric materials and a passive electrical (shunt) network. The piezoelectric materials convert vibration energy into electrical energy and then dissipate the electrical energy in the form of joule heating through the passive electrical (shunt) network, which is also known as passive vibration damping.

The electrical (shunt) network consists of resistors, capacitors and inductors. The network is connected across a PZT transducer, which can be modeled as a strain controlled voltage source in series with an inherent capacitance, or a strain controlled current source in parallel with the inherent capacitance. The PZT transducer alters the stiffness and loss factor of the system to be attached. It acts as a Tuned Mass Damper (TMD) or tuned vibration absorber (TVA).

It is widely reported $[1,2,4,5]$ that significant amount of vibration is removed when resistor-inductor (RL) or resistor-inductor-capacitor (RLC) shunt circuits are optimally tuned.

Though our study, we conclude that in order to maximize the vibration energy to be shunted by the PZT, it is preferred to transfer more energy from a structure onto the PZT. Simulation and experimental results show that the 
material property of the structure affects the energy transfer between the structure and the PZT.

\section{Equation of motion of a composite beam}

The "piezoelectric effect" was first discovered by Pierre Curie and his brother Jacques in 1880 . When a crystal is under pressure, an electrical potential appears across some of its faces (direct effect). When an electrical field is applied, mechanical deformation of the crystal occurs (converse effect). The most common material possessing the piezoelectric effect is Lead-ZirconiumTitanium (PZT). The piezoelectric effect indicates that there is energy conversion or transduction from one form to another occurring during the deformation process. For passive vibration shunting with piezoelectric material, the "direct effect" is used. The piezoelectric material has the linear constitutive relation

$$
\left[\begin{array}{c}
\sigma \\
\mathbf{E}
\end{array}\right]=\left[\begin{array}{cc}
\mathbf{E}_{\mathbf{p}} & -\mathbf{h} \\
-\mathbf{h} & \beta
\end{array}\right] \cdot\left[\begin{array}{c}
\varepsilon \\
\mathbf{D}
\end{array}\right]
$$

where $\varepsilon$ is the mechanical strain matrix of PZT, $\sigma$ is the mechanical stress matrix of PZT $(\mathrm{Pa}), \mathbf{E}$ is the electrical field matrix of PZT $(\mathrm{V} / \mathrm{m}), \mathbf{D}$ is the electrical displacement matrix of PZT $\left(\mathrm{C} / \mathrm{m}^{2}\right), \mathbf{E}_{\mathbf{p}}$ is the elastic modulus matrix of PZT $(\mathrm{Pa}), \beta$ is the dielectric impermeability matrix of PZT $(\mathrm{m} / \mathrm{F})$, $\mathbf{h}$ is the electrical displacement-stress coefficient matrix of PZT $(\mathrm{V} / \mathrm{m})$.

In this article, "composite material" refers to a polymeric (epoxy) carbonfibre material while "composite beam" refers to beam made of more than one material. The composite beam shown in Figure 1 is a rectangular beam with a PZT patch attached.

Euler-Bernoulli beam theory is used to model the composite beam which means that only bending deformation are considered, shear and rotation 


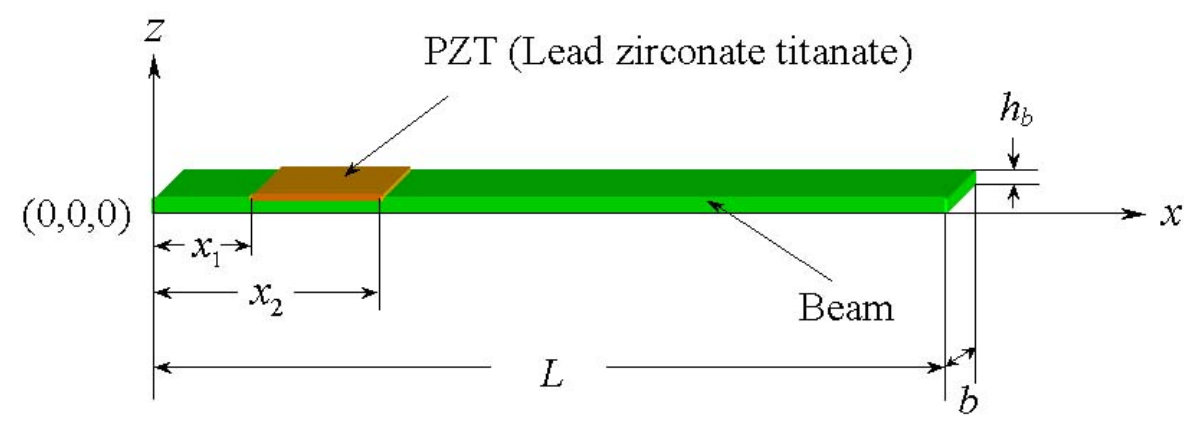

FiguRE 1: PZT attached to the composite beam.

deformations are ignored. The potential energy of beam due to bending is

$$
U_{b}=\frac{1}{2} \int_{V_{b}} \sigma_{11} \varepsilon_{11} d V_{b}=\frac{1}{2} \int_{0}^{L} E_{b} I_{b}\left(\frac{\partial^{2} w}{\partial x^{2}}\right)^{2} d x .
$$

The potential energy of PZT due to bending is

$$
\begin{aligned}
U_{p}= & \frac{1}{2} \int_{V_{p}}\left(\sigma_{11} \varepsilon_{11}+D E\right) d V_{p} \\
= & \frac{1}{2} \int_{0}^{L}\left[E_{p} I_{p}\left(\frac{\partial^{2} w}{\partial x^{2}}\right)^{2}+\frac{1}{2} h_{31} A_{p}\left(h_{b}+h_{p}\right) D \frac{\partial^{2} w}{\partial x^{2}}+A_{p} \beta_{33} D^{2}\right] \\
& \times\left[H\left(x-x_{1}\right)-H\left(x-x_{2}\right)\right] d x,
\end{aligned}
$$

where $\varepsilon_{11}$ is the axial strain in $x$ direction, $\sigma_{11}$ is the axial stress in $x$ direction $(\mathrm{Pa}), w$ is the transverse displacement $(\mathrm{m}), I_{b}=b h_{b}^{3} / 12+\left(\bar{z}-z_{b}\right)^{2} A_{b}$ is the area moment of inertia about the neutral axis $\left(\mathrm{m}^{4}\right), I_{p}=b h_{p}^{3} / 12+(\bar{z}-$ $\left.z_{p}\right)^{2} A_{p}$ is the area moment of inertia about the neutral axis $\left(\mathrm{m}^{4}\right)$,

$$
\bar{z}=\frac{\sum_{i=1}^{n} A_{i} E_{i} z_{i}}{\sum_{i=1}^{n} A_{i} E_{i}}=\frac{A_{b} E_{b} z_{b}+A_{p} E_{p} z_{p}}{A_{b} E_{b}+A_{p} E_{p}}
$$

is the neutral axis of composite beam $(\mathrm{m})$, and $H(x)$ is the Heaviside function. The total potential energy is $U=U_{b}+U_{p}$. The kinetic energy of beam due 
to bending is

$$
T_{b}=\frac{1}{2} \int_{0}^{L} \rho_{b} A_{b}\left(\frac{\partial w}{\partial t}\right)^{2} d x .
$$

The kinetic energy of PZT due to bending is

$$
T_{p}=\frac{1}{2} \int_{0}^{L} \rho_{p} A_{p}\left(\frac{\partial w}{\partial t}\right)^{2}\left[H\left(x-x_{1}\right)-H\left(x-x_{2}\right)\right] d x .
$$

The total kinetic energy is $T=T_{b}+T_{p}$. According to Hamilton's principle

$$
\delta \int_{t_{1}}^{t_{2}}(T-U+W) d t=\int_{t_{1}}^{t_{2}}\left(\delta T-\delta U+\delta W_{f}+\delta W_{p}\right) d t=0,
$$

where $\delta W$ represents virtual work, $\delta W_{p}$ is the virtual work due to electrical displacement, $\delta W_{f}$ is the virtual work due to applied force

$$
\delta W_{p}=\int_{V_{p}} E \delta D d V_{p}
$$

and

$$
\delta W_{f}=\delta \int_{0}^{L} f(x, t) w(x, t) d x .
$$

The motion equation of the composite beam therefore is

$$
\begin{aligned}
& E_{b} I_{b} \frac{\partial^{4} w}{\partial x^{4}}+E_{p} I_{p} \frac{\partial^{4} w}{\partial x^{4}}\left[H\left(x-x_{1}\right)-H\left(x-x_{2}\right)\right] \\
& +2 E_{p} I_{p} \frac{\partial^{3} w}{\partial x^{3}}\left[\delta\left(x-x_{1}\right)-\delta\left(x-x_{2}\right)\right] \\
& +E_{p} I_{p} \frac{\partial^{2} w}{\partial x^{2}}\left[\delta^{\prime}\left(x-x_{1}\right)-\delta^{\prime}\left(x-x_{2}\right)\right]+\rho_{b} A_{b} \frac{\partial^{2} w}{\partial t^{2}} \\
& +\rho_{p} A_{p} \frac{\partial^{2} w}{\partial t^{2}}\left[H\left(x-x_{1}\right)-H\left(x-x_{2}\right)\right] \\
& -h_{31} A_{p}\left(h_{b}+\frac{h_{p}}{2}\right) D_{3}\left[\delta^{\prime}\left(x-x_{1}\right)-\delta^{\prime}\left(x-x_{2}\right)\right]=f(x, t),
\end{aligned}
$$


with boundary conditions

$$
\begin{aligned}
& \left.E_{b} I_{b} \frac{\partial^{2} w}{\partial x^{2}} \delta\left(\frac{\partial w}{\partial x}\right)\right|_{0} ^{L}=0 \Rightarrow \frac{\partial^{2} w}{\partial x^{2}}=0 \quad \text { or } \quad \delta\left(\frac{\partial w}{\partial x}\right)=0, \\
& \left.E_{b} I_{b} \frac{\partial^{3} w}{\partial x^{3}} \delta w\right|_{0} ^{L}=0 \Rightarrow \frac{\partial^{3} w}{\partial x^{3}}=0 \quad \text { or } \quad \delta w=0 .
\end{aligned}
$$

\section{Composite beam with parallel RL shunt networks}

According to the mode separation method

$$
w(x, t)=\sum_{r=1}^{\infty} \phi_{r}(x) q_{r}(t) \approx \sum_{r=1}^{N} \phi_{r}(x) q_{r}(t),
$$

where $\phi_{r}(x)$ satisfies all the boundary conditions, and $q_{r}(t)$ is time function.

Substitute Equation (11) into Equation (9), using Galerkin's method, the partial differential equation of Equation (9) is discretized into an ordinary differential equation as shown below:

$$
\begin{aligned}
& E_{b} I_{b} \sum_{r=1}^{N} \phi_{r}^{(4)}(x) q_{r}(t)+E_{p} I_{p} \sum_{r=1}^{N} \phi_{r}^{(4)} q_{r}(t)\left[H\left(x-x_{1}\right)-H\left(x-x_{2}\right)\right] \\
& +2 E_{p} I_{p} \sum_{r=1}^{N} \phi_{r}^{(3)} q_{r}(t)\left[\delta\left(x-x_{1}\right)-\delta\left(x-x_{2}\right)\right]+E_{p} I_{p} \sum_{r=1}^{N} \phi_{r}^{\prime \prime}(x) q_{r}(t)\left[\delta^{\prime}\left(x-x_{1}\right)\right. \\
& +\rho_{b} A_{b} \sum_{r=1}^{N} \phi_{r}(x) \ddot{q}_{r}(t)+\rho_{p} A_{p}\left[H\left(x-x_{1}\right)-H\left(x-x_{2}\right)\right] \sum_{r=1}^{N} \phi_{r}(x) \ddot{q}_{r}(t) \\
& -h_{31} A_{p}\left(h_{b}+\frac{h_{p}}{2}\right) D_{3}\left[\delta^{\prime}\left(x-x_{1}\right)-\delta^{\prime}\left(x-x_{2}\right)\right]-f(x, t)=\varepsilon
\end{aligned}
$$


$\operatorname{minimizing} \varepsilon$ by $\left\langle\varepsilon, \phi_{s}\right\rangle=0$,

$$
\int_{0}^{L} \varepsilon(x, t) \phi_{s}(x) d x=0, \quad s=1,2, \ldots, N
$$

obtains

$$
\begin{aligned}
& \sum_{r=1}^{N}\left(\int_{0}^{L}\left[\rho_{b} A_{b}+\rho_{p} A_{p}\left[H\left(x-x_{1}\right)-H\left(x-x_{2}\right)\right]\right] \phi_{r}(x) \phi_{s}(x) d x\right) \ddot{q}_{r}(t) \\
& +\sum_{r=1}^{N}\left(\int_{0}^{L}\left[E_{b} I_{b}+E_{p} I_{p}\left[H\left(x-x_{1}\right)-H\left(x-x_{2}\right)\right]\right] \phi_{r}^{\prime \prime}(x) \phi_{s}^{\prime \prime}(x) d x\right) q_{r}(t) \\
& -\frac{h_{31} A_{p}}{\beta_{33}}\left(h_{b}+\frac{h_{p}}{2}\right) D_{3} \int_{x_{1}}^{x_{2}} \phi_{s}^{\prime \prime}(x) d x=\int_{0}^{L} f(x, t) \phi_{s}(x) d x
\end{aligned}
$$

where

$$
D_{3}=\frac{1}{\beta_{33}}\left(E_{3}+h_{31} \varepsilon_{11}\right)=\frac{1}{\beta_{33}}\left(\frac{v(t)}{h_{p}}+h_{31} \varepsilon_{11}\right) .
$$

When a parallel RL shunt circuit is connected across the electrodes of the PZT, the electrical current due to electrical charge generated from the mechanical stress flows to the RL shunt circuit. According to Kirchhoff's laws, this is

$$
i(t)=-\frac{d Q}{d t}=-S_{p} \frac{d D_{3}}{d t}=-C_{p} \frac{d v(t)}{d t}-h_{31} h_{p} C_{p} \frac{d \varepsilon_{11}}{d t}=i_{L}(t)+i_{R}(t)
$$

where $C_{p}=S_{p} /\left(\beta_{33} h_{p}\right), Q$ is the electrical charge of PZT, $S_{p}$ is the surface area of PZT. Equation (17) can be rewritten as

$$
i_{C}+i_{L}+i_{R}=-I_{S},
$$

where $i_{C}=C_{p} \frac{d v}{d t}$ is the electrical current in $C_{p}$, where $i_{L}$ and $i_{R}$ are electrical currents in the inductor and resistor of shunt circuit respectively, and where $I_{S}=h_{31} h_{p} C_{p} \frac{d \varepsilon_{11}}{d t}$ is the electrical current generated due to the mechanical stress. The circuit model of Equation (18) is depicted in Figure 2 that represents the parallel RL shunt circuit. The voltage $v(t)$ is obtained 


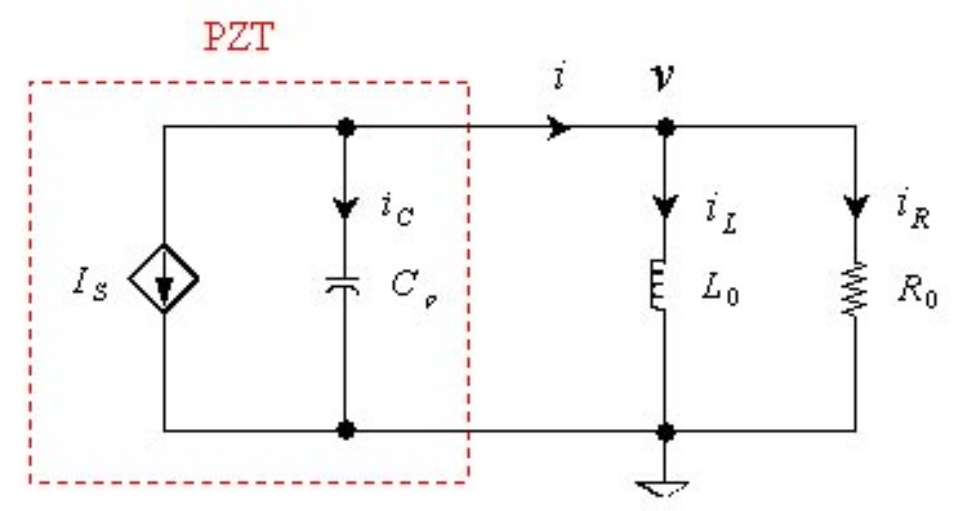

FigURE 2: Equivalent circuit of parallel RL shunt.

from

$$
\begin{aligned}
v(t)=\frac{1}{C_{p}} \int i_{C} d t & =-\frac{1}{C_{p}} \int\left(h_{31} h_{p} C_{p} \frac{d \varepsilon_{11}}{d t}+i_{R}+i_{L}\right) d t \\
& =-\frac{1}{C_{p}} \int\left(h_{31} h_{p} C_{p} \frac{d \varepsilon_{11}}{d t}+\frac{L_{0}}{R_{0}} \frac{d i_{L}}{d t}+i_{L}\right) d t \\
& =-h_{31} h_{p} \varepsilon_{11}-\frac{L_{0}}{R_{0} C_{p}} i_{L}-\frac{1}{C_{p}} \int i_{L} d t
\end{aligned}
$$

Substituting Equation (19) into Equation (16) obtains

$$
D_{3}=-\frac{1}{\beta_{33} h_{p}}\left(\frac{L_{0}}{R_{0} C_{p}} i_{L}+\frac{1}{C_{p}} \int i_{L} d t\right) .
$$

Then Equation (15) becomes

$$
\begin{aligned}
& \sum_{r i=1}^{N}\left(\int_{0}^{L}\left[\rho_{b} A_{b}+\rho_{p} A_{p}\left[H\left(x-x_{1}\right)-H\left(x-x_{2}\right)\right]\right] \phi_{r}(x) \phi_{s}(x) d x\right) \ddot{q}_{r}(t) \\
& +\sum_{r i=1}^{N}\left(\int_{0}^{L}\left[\rho_{b} A_{b}+\rho_{p} A_{p}\left[H\left(x-x_{1}\right)-H\left(x-x_{2}\right)\right]\right] \phi_{r}(x) \phi_{s}(x) d x\right) q_{r}(t)
\end{aligned}
$$




$$
+B_{L} i_{L}+B_{R} \int i_{L} d t=\int_{0}^{L} f(x, t) \phi_{s}(x) d x
$$

where

$$
\begin{aligned}
& B_{L}=\frac{h_{31} h_{p}\left(2 h_{b}+h_{p}\right)}{2\left(x_{2}-x_{1}\right)} \frac{L_{0}}{R_{0}} \int_{x_{1}}^{x_{2}} \phi_{s}^{\prime \prime}(s) d x, \\
& B_{R}=\frac{h_{31} h_{p}\left(2 h_{b}+h_{p}\right)}{2\left(x_{2}-x_{1}\right)} \int_{x_{1}}^{x_{2}} \phi_{s}^{\prime \prime}(s) d x .
\end{aligned}
$$

On the other hand, since $v(t)=L_{0} \frac{d i_{L}}{d t}$ and combining this with Equation (19), thus

$$
L_{0} \frac{d i_{L}}{d t}=-h_{31} h_{p} \varepsilon_{11}-\frac{L_{0}}{R_{0} C_{p}} i_{L}-\frac{1}{C_{p}} \int i_{L} d t
$$

or

$$
L_{0} \frac{d i_{L}}{d t}+\frac{L_{0}}{R_{0} C_{p}} i_{L}+\frac{1}{C_{p}} \int i_{L} d t=h_{31} h_{p} z \frac{\partial^{2} w}{\partial x^{2}},
$$

where strain $\varepsilon_{11}$ has been replaced by $-z \frac{\partial^{2} w}{\partial x^{2}}$. Integrating both sides of Equation (24) and considering equation $\frac{\partial^{2} w}{\partial x^{2}}=\left(\sum_{r=1}^{N} \phi_{r}^{\prime \prime}(x)\right) q_{r}(t)$,

$$
\int_{V_{p}}\left(L_{0} \frac{d i_{L}}{d t}+\frac{L_{0}}{R_{0} C_{p}} i_{L}+\frac{1}{C_{p}} \int i_{L} d t\right) d V_{p}=h_{31} h_{p} \int_{V_{p}} z \frac{\partial^{2} w}{\partial x^{2}} d V_{p},
$$

or

$$
\begin{aligned}
& \int_{x_{1}}^{x_{2}}\left\{b \int_{h_{b}}^{h_{b}+h_{p}}\left(L_{0} \frac{d i_{L}}{d t}+\frac{L_{0}}{R_{0} C_{p}} i_{L}+\frac{1}{C_{p}} \int i_{L} d t\right) d z\right\} d x \\
= & h_{31} h_{p} \int_{x_{1}}^{x_{2}} b \int_{h_{b}}^{h_{b}+h_{p}} z \frac{\partial^{2} w}{\partial x^{2}} d z d x,
\end{aligned}
$$

one can have

$$
\frac{d i_{L}}{d t}+\frac{1}{R_{0} C_{p}} i_{L}+\frac{1}{L_{0} C_{p}} \int i_{L} d t-\frac{h_{31} h_{p}\left(h_{b}+\frac{h_{p}}{2}\right)}{\left(x_{2}-x_{1}\right) L_{0}}\left(\sum_{r=1}^{N} \int_{x_{1}}^{x_{2}} \phi_{r}^{\prime \prime}(x) d x\right) q_{r}=0 .
$$


Equation (21) is written in a concise form as

$$
\sum_{r=1}^{N} m_{s r} \ddot{q}_{r}+\sum_{r=1}^{N} k_{s r} q_{r}+B_{L} i_{L}+B_{R} \int i_{L} d t=f_{d}(t) .
$$

Equation (26) is written as

$$
\frac{d i_{L}}{d t}+c_{R} i_{L}+c_{L} \int i_{L} d t+\sum_{r=1}^{N} \Phi_{r} q_{r}=0,
$$

where $c_{R}=1 /\left(R_{0} C_{p}\right)$ and $c_{L}=1 /\left(L_{0} C_{p}\right)$, respectively,

$$
\begin{aligned}
\Phi_{r} & =-\frac{h_{31} h_{p}\left(h_{b}+\frac{h_{p}}{2}\right)}{\left(x_{2}-x_{1}\right) L_{0}} \int_{x_{1}}^{x_{2}} \phi_{r}^{\prime \prime}(x) d x \\
m_{s r} & =\int_{0}^{L}\left[\rho_{b} A_{b}+\rho_{p} A_{p}\left[H\left(x-x_{1}\right)-H\left(x-x_{2}\right)\right]\right] \phi_{r}(x) \phi_{s}(x) d x \\
k_{s r} & =\int_{0}^{L}\left[E_{b} I_{b}+E_{p} I_{p}\left[H\left(x-x_{1}\right)-H\left(x-x_{2}\right)\right]\right] \phi_{r}^{\prime \prime}(x) \phi_{s}^{\prime \prime}(x) d x \\
f_{d} & =\int_{0}^{L} f(x, t) \phi_{s}(x) d x=\int_{0}^{L} F_{d}(t) \delta\left(x-x_{d}\right) \phi_{s}(x) d x
\end{aligned}
$$

\section{Numerical example}

By making $\phi_{r}(x)=\sin (r \pi x / L), r=1,2, \ldots, N$, which satisfies all boundary conditions (Hinged-Hinged), Equations (29), (22) and (23) are

$$
\begin{aligned}
\Phi_{r} & =\frac{h_{31} h_{p}\left(h_{b}+\frac{h_{p}}{2}\right) r \pi}{\left(x_{2}-x_{1}\right) L}\left[\cos \left(\frac{r \pi x_{1}}{L}\right)-\cos \left(\frac{r \pi x_{2}}{L}\right)\right], \quad r=1, \ldots, N,(33) \\
B_{L} & =\frac{h_{31}\left(h_{b}+\frac{h_{p}}{2}\right) L_{0} s \pi}{L R_{0}}\left[\cos \left(\frac{s \pi x_{1}}{L}\right)-\cos \left(\frac{s \pi x_{2}}{L}\right)\right], \quad s=1, \ldots, N,(34)
\end{aligned}
$$




$$
B_{R}=\frac{h_{31}\left(h_{b}+\frac{h_{p}}{2}\right) s \pi}{L}\left[\cos \left(\frac{s \pi x_{1}}{L}\right)-\cos \left(\frac{s \pi x_{2}}{L}\right)\right], \quad s=1, \ldots, N .
$$

For $s=r$,

$$
\begin{aligned}
m_{r r}= & \frac{\rho_{b} A_{b} L+\rho_{p} A_{p}\left(x_{2}-x_{1}\right)}{2} \\
+ & \frac{\rho_{p} A_{p} L}{2 \pi r}\left[\sin \left(\frac{2 \pi r x_{1}}{L}\right)-\sin \left(\frac{2 \pi r x_{2}}{L}\right)\right], \\
k_{r r}= & \left(\frac{r \pi}{L}\right)^{4}\left\{\frac{E_{b} I_{b} L+E_{p} I_{p}\left(x_{2}-x_{1}\right)}{2}\right. \\
& \left.+\frac{E_{p} I_{p} L}{2 \pi r}\left[\sin \left(\frac{2 \pi r x_{1}}{L}\right)-\sin \left(\frac{2 \pi r x_{2}}{L}\right)\right]\right\} .
\end{aligned}
$$

For $s \neq r$,

$$
\begin{aligned}
m_{s r}= & \frac{\rho_{p} A_{p} L}{\pi\left(r^{2}-s^{2}\right)}\left(r \sin \frac{s \pi x_{1}}{L} \cos \frac{r \pi x_{1}}{L}-s \sin \frac{r \pi x_{1}}{L} \cos \frac{s \pi x_{1}}{L}\right. \\
& \left.-r \sin \frac{s \pi x_{2}}{L} \cos \frac{r \pi x_{2}}{L}+s \sin \frac{r \pi x_{2}}{L} \cos \frac{s \pi x_{2}}{L}\right) \\
k_{s r}= & \frac{E_{p} I_{p} L}{\left(r^{2}-s^{2}\right) \pi}\left(\frac{r s \pi^{2}}{L^{2}}\right)^{2}\left(r \sin \frac{s \pi x_{1}}{L} \cos \frac{r \pi x_{1}}{L}-s \sin \frac{r \pi x_{1}}{L} \cos \frac{s \pi x_{1}}{L}\right. \\
& \left.-r \sin \frac{s \pi x_{2}}{L} \cos \frac{r \pi x_{2}}{L}+s \sin \frac{r \pi x_{2}}{L} \cos \frac{s \pi x_{2}}{L}\right)
\end{aligned}
$$

The matrix form of Equation (27) is

$$
\mathbf{M} \ddot{\mathbf{q}}+\mathbf{K q}+\mathbf{B}_{\mathbf{L}} \mathbf{i}_{\mathbf{L}}+\mathbf{B}_{\mathbf{R}} \tilde{\mathbf{i}}_{\mathbf{L}}=\mathbf{f}_{\mathbf{d}} .
$$

When considering internal structural damping, Equation (40) is extended to

$$
\mathbf{M} \ddot{\mathbf{q}}+\mathbf{C} \dot{\mathbf{q}}+\mathbf{K q}+\mathbf{B}_{\mathbf{L}} \mathbf{i}_{\mathbf{L}}+\mathbf{B}_{\mathbf{R}} \tilde{\mathbf{i}}_{\mathbf{L}}=\mathbf{f}_{\mathbf{d}}
$$

where

$$
\mathbf{C}=\alpha \mathbf{M}+\gamma \mathbf{K}
$$


The matrix form of Equation (28) is

$$
\dot{\mathbf{i}}_{\mathbf{L}}+\mathrm{C}_{\mathbf{R}} \mathbf{i}_{\mathbf{L}}+\mathrm{C}_{\mathbf{L}} \tilde{\mathbf{i}}_{\mathbf{L}}+\Phi q=\mathbf{0},
$$

where

$$
\tilde{\mathbf{i}}_{\mathbf{L}}=\int \mathbf{i}_{\mathbf{L}} d t
$$

Convert Equation (41) and (42) to state space form

$$
\begin{aligned}
& \dot{\mathbf{x}}=\mathbf{A}_{\mathbf{S}} \mathbf{x}+\mathbf{B}_{\mathbf{S}} \mathbf{u}, \\
& \mathbf{y}=\mathbf{C}_{\mathbf{S}} \mathbf{x}+\mathbf{D}_{\mathbf{S}} \mathbf{u},
\end{aligned}
$$

where

$$
\begin{aligned}
& \mathbf{x}=\left[\begin{array}{llll}
\mathbf{x}_{\mathbf{1}} & \mathbf{x}_{\mathbf{2}} & \mathbf{x}_{\mathbf{3}} & \mathbf{x}_{\mathbf{4}}
\end{array}\right]_{4 N \times 1}^{\mathbf{T}}=\left[\begin{array}{llll}
\mathbf{q} & \dot{\mathbf{q}} & \tilde{\mathbf{i}}_{\mathbf{L}} & \mathbf{i}_{\mathbf{L}}
\end{array}\right]_{4 N \times 1}^{\mathbf{T}}, \quad \mathbf{u}=\left[\mathbf{f}_{\mathbf{d}}\right]_{4 N \times 1}, \\
& \mathbf{A}_{\mathbf{S}}=\left[\begin{array}{cccc}
\mathbf{0} & \mathbf{I} & \mathbf{0} & \mathbf{0} \\
-\mathbf{M}^{-1} \mathbf{K} & -\mathbf{M}^{-1} \mathbf{C} & -\mathbf{M}^{-1} \mathbf{B}_{\mathbf{R}} & -\mathbf{M}^{-\mathbf{1}} \mathbf{B}_{\mathbf{L}} \\
\mathbf{0} & \mathbf{0} & \mathbf{0} & \mathbf{I} \\
-\boldsymbol{\Phi} & \mathbf{0} & -\boldsymbol{\Gamma} & -\boldsymbol{\Omega}
\end{array}\right]_{4 N \times 4 N} \\
& \mathbf{B}_{\mathbf{S}}=\left[\begin{array}{c}
\mathbf{0} \\
\mathbf{M}^{-\mathbf{1}} \\
\mathbf{0} \\
\mathbf{0}
\end{array}\right]_{4 N \times N}, \quad \mathbf{C}_{\mathbf{S}}=\left[\begin{array}{llll}
\mathbf{C}_{\mathbf{1}} & \mathbf{0} & \mathbf{0} & \mathbf{0}
\end{array}\right]_{1 \times 4 N} \\
& \mathbf{C}_{\mathbf{1}}=\left[\begin{array}{lll}
\sin \frac{\pi x_{m}}{L} & \cdots & \sin \frac{N \pi x_{m}}{L}
\end{array}\right]_{1 \times N}, \quad \mathbf{D}_{\mathbf{S}}=[\mathbf{0}]_{1 \times N}, \\
& \boldsymbol{\Gamma}=\left[\begin{array}{ccc}
\frac{1}{C_{P} R_{1}} & & 0 \\
0 & \ddots & \frac{1}{C_{P} R_{N}}
\end{array}\right], \boldsymbol{\Omega}=\left[\begin{array}{ccc}
\frac{1}{C_{P} L_{1}} & & 0 \\
0 & & \frac{1}{C_{P} L_{N}}
\end{array}\right] \text {, } \\
& \boldsymbol{\Phi}=\left[\begin{array}{ccc}
\Phi_{1} & & 0 \\
& \ddots & \\
0 & & \Phi_{N}
\end{array}\right] \text {. }
\end{aligned}
$$

Given an aluminium beam and a PZT, where the parameters are 


\section{Beam}

$$
\begin{gathered}
V_{b}=0.5 \times 0.025 \times 0.003 \mathrm{~m}^{3}, \quad \rho_{b}=2700 \mathrm{Kg} / \mathrm{m}^{3} \\
E_{b}=70 \mathrm{GPa}, \quad \alpha=0.2, \quad \gamma=10^{-7}, \quad x_{d}=0.125 \mathrm{~m} .
\end{gathered}
$$

\section{PZT}

$$
\begin{array}{r}
V_{p}=0.06 \times 0.025 \times 0.00025 \mathrm{~m}^{3}, \quad x_{1}=0.095 \mathrm{~m}, \quad x_{2}=0.155 \mathrm{~m}, \\
\rho_{p}=7600 \mathrm{Kg} / \mathrm{m}^{3}, \quad E_{p}=70 \mathrm{GPa}, \quad h_{31}=7.65 \times 10^{8} \mathrm{~V} / \mathrm{m}, \\
\beta_{33}=7.33 \times 10^{7} \mathrm{~m} / \mathrm{F}, \quad C_{p}=\frac{S_{p}}{\beta_{33} h_{p}}=82 \times 10^{-9} \mathrm{~F} .
\end{array}
$$

Shunt circuit components to target the first mode are

$$
\begin{gathered}
L_{1}=400 \mathrm{H}, \quad L_{2}=24.64 \mathrm{H}, \quad L_{3}=4.846 \mathrm{H}, \\
R_{1}=340 \mathrm{k} \Omega, \quad R_{2}=100 \mathrm{k} \Omega, \quad R_{3}=70 \mathrm{k} \Omega .
\end{gathered}
$$

Solving the state space Equation (43) with MATLAB obtains the impulse responses and frequency response of the composite beam with a force vector $\mathbf{f}_{\mathrm{d}}=10^{-2}\left[\begin{array}{lll}1 & 1 & 1\end{array}\right]^{T}$ (which is equivalent to have equal point force being applied at the anti-node of each mode) and vibration measured at $x_{m}=L / 4$ from origin resulting in $C_{1}(r)=\sin \left(r \pi x_{m} / L\right)=\sin (r \pi / 4), r=1,2,3$, as shown in Figure 3. The natural frequencies of the composite beam are approximately 28,112 , and $252 \mathrm{~Hz}$ respectively. Figure 3 shows that the vibration amplitude of the beam is significantly reduced when the inductor of shunt circuit is tuned to the frequency to be controlled, that is,

$$
L_{i}=\frac{1}{\left(2 \pi f_{i}\right)^{2} C_{p}} .
$$

However, the RL shunt control possesses narrowband characteristics which it is sensitive to the mismatch between the frequency of shunt circuit and the natural frequency to be controlled. When the shunt circuit is ill-tuned, the control becomes worse. Figure 4 is the simulation when $L_{1}=365 \mathrm{H}$ which gives the control frequency of the shunt circuit about $29 \mathrm{~Hz}, 1 \mathrm{~Hz}$ off the center frequency of the first mode. The control effect is slightly worse when compared with that in Figure 3. 


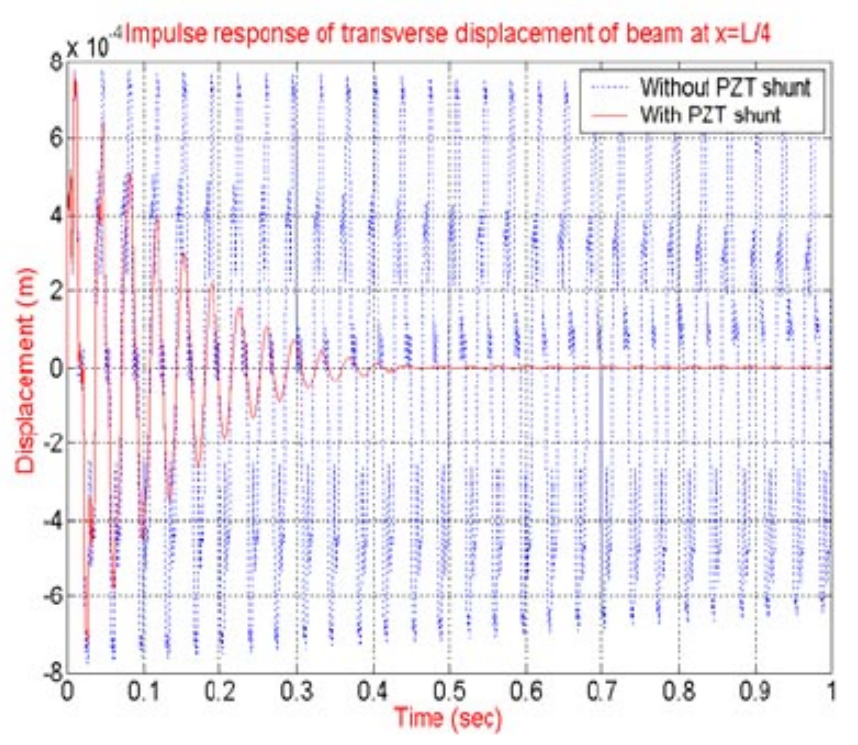

(a) Impulse response

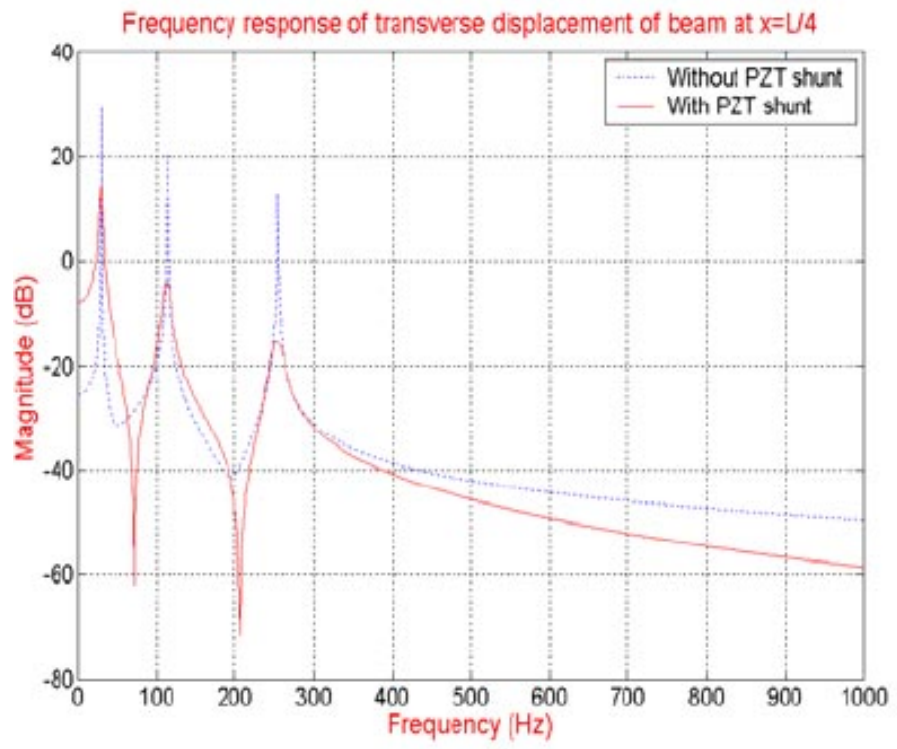

(b) Frequency response

FigURE 3: Impulse and frequency responses of composite beam at $x_{m}=L / 4$, $L_{1}=400 \mathrm{H}$ 


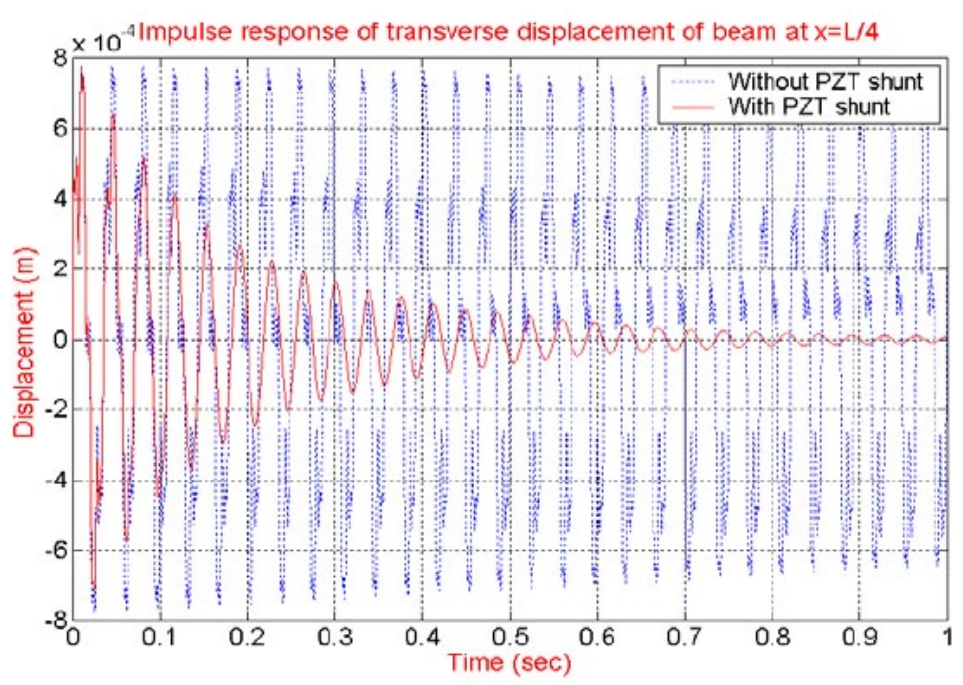

Figure 4: Shunt circuit off-tuned (when $L_{1}=365 \mathrm{H}$ )

\section{Simulation of passive piezoelectric vibration shunt with ansys}

Efficient vibration shunt control involves determining the optimum size of PZT patches and location to place them in order to achieve optimal performance and minimize cost. However, each PZT patch has to be firmly glued on the structure before it can take effect. Therefore, the PZT patch becomes unusable after being glued. Therefore, it will be quite expensive in both time and resources if experiments alone are carried out. It is desirable to have some method to determine the optimal size and location of PZT patch before it is attached to a structure. Since the Finite Element Analysis (FEA) software package ANSYS has a coupled field capability (SOLID5 is the 3D coupled field solid element and CIRCU94 is the piezoelectric circuit element), it has the means to construct a RL electrical shunt network connected across a piezoelectric patch bonded on a structure to simulate piezoelectric vibration 
shunt control.

The object used for modeling is a $0.5 \times 0.025 \times 0.003 \mathrm{~m}^{3}$ aluminum beam with a $0.05 \times 0.025 \times 0.0005 \mathrm{~m}^{3}$ PZT patch attached. The boundary condition of the beam is "clamped-free". The element for modeling aluminum beam is SOLID45, a 3D structure solid element. The density and Young's modulus of the aluminum beam are $\rho_{b}=2700 \mathrm{Kg} / \mathrm{m}^{3}$ and $E_{b}=66 \mathrm{GPa}$ respectively. The element for modeling piezoelectric transducer PZT is SOLID5, a 3D coupled field solid element. The density and Young's modulus of the PZT are $\rho_{p}=$ $7730 \mathrm{Kg} / \mathrm{m}^{3}$ and $E_{p}=66 \mathrm{GPa}$ respectively. The element for modeling shunt circuit component (resistor and inductor) is CIRCU94, a circuit element.

Figure 5 is the ANSYS model of the structure with PZT attached. A parallel RL circuit is connected across the electrodes of PZT. The inherent static capacitance of the PZT measured was about $C_{p}=31.4 \mathrm{nF}$.

Figure 6 shows the harmonic analysis of the single mode parallel RL shunt. The shunt circuit has been tuned individually to target the mode to be controlled. (a) is the spectrum before shunt, (b)-(d) are the spectra of the first to third modes after shunt respectively. The graphs show that the amplitudes of the first to third modes have been reduced by about $84 \%, 70 \%$ and $80 \%$, (or $16 \mathrm{~dB}, 10.5 \mathrm{~dB}$, and $14 \mathrm{~dB}$ ) respectively.

\section{ANASYS simulation with different material properties}

The ANASYS simulation results in Figure 6 show that with the shunt control the vibration amplitude of aluminum beam at natural frequencies can be significantly reduced. However, simulation showed that the effectiveness of the shunt control on beam is dramatically worsened when the beam material is changed to wood. 
6 ANASYS simulation with different material properties

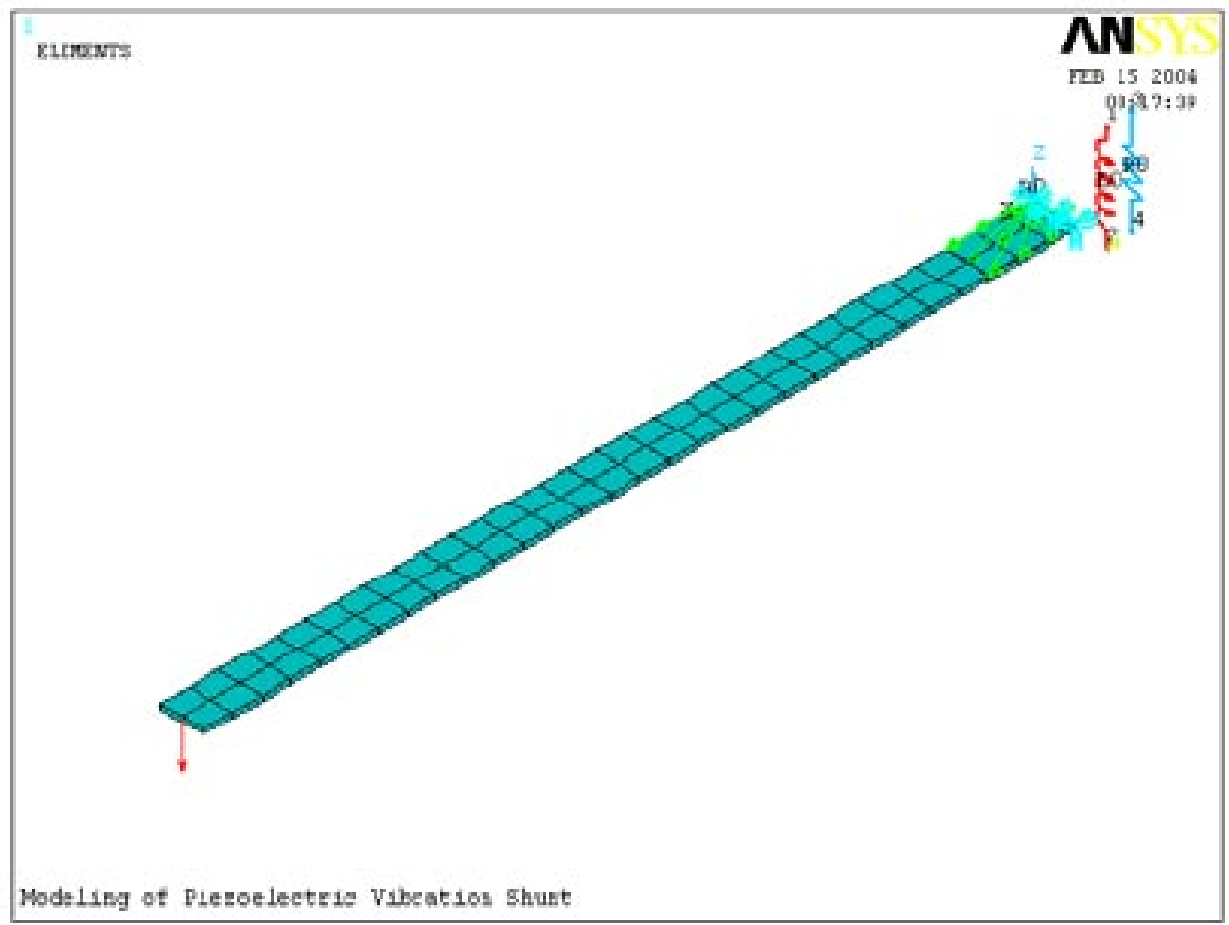

FiguRE 5: Modeling of single mode parallel RL piezoelectric shunt on a cantilever beam with ANSYS 


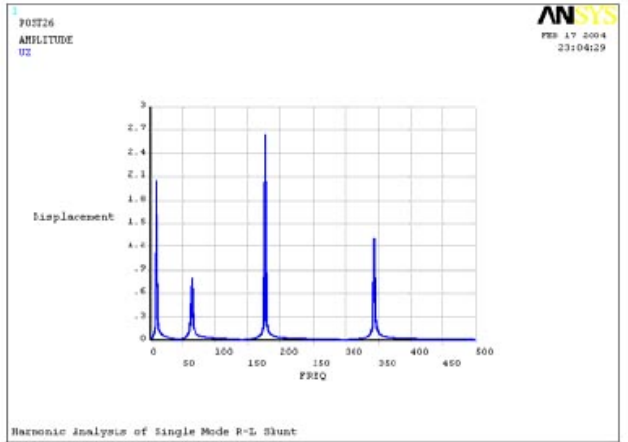

(a) Before Shunt

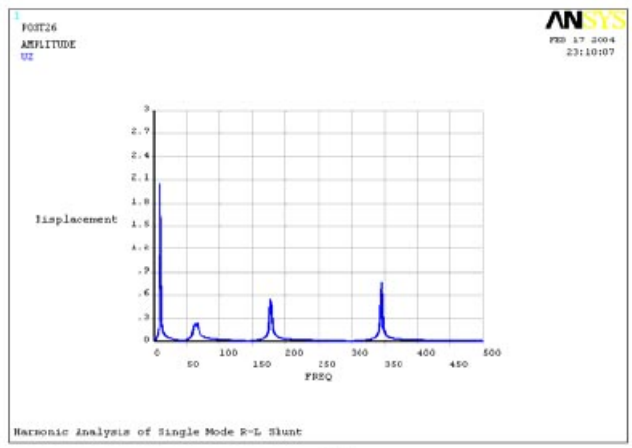

(c) Shunt $2^{\text {nd }}$ mode

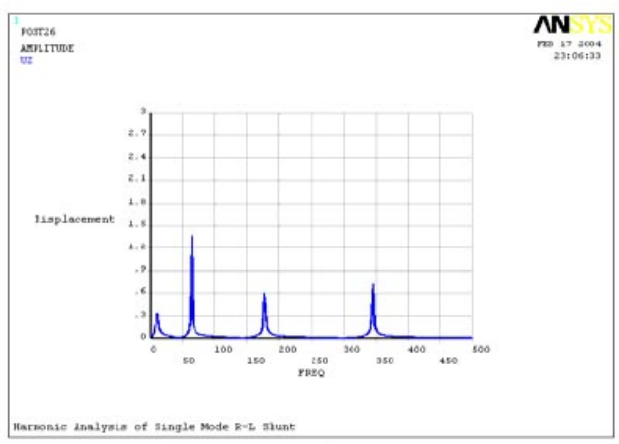

(b) Shunt $1^{\text {st }}$ mode

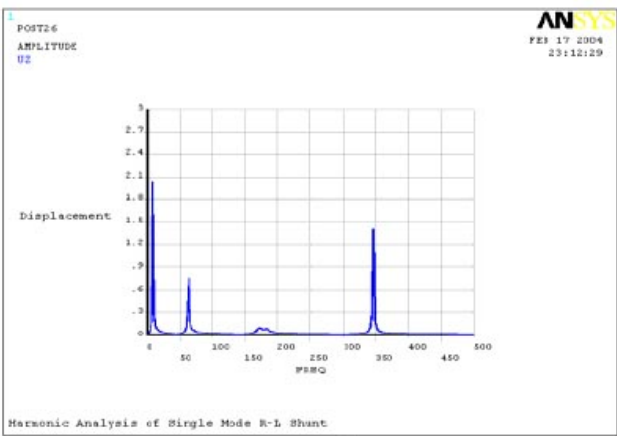

(d) Shunt $3^{\text {rd }}$ mode

FiguRE 6: Harmonic analysis of the aluminum beam vibration 


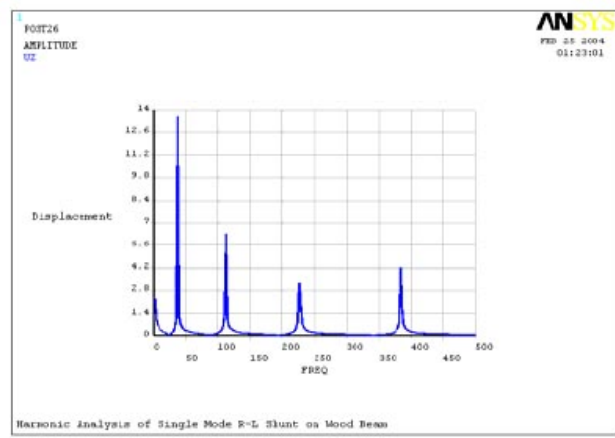

(a) Before Shunt

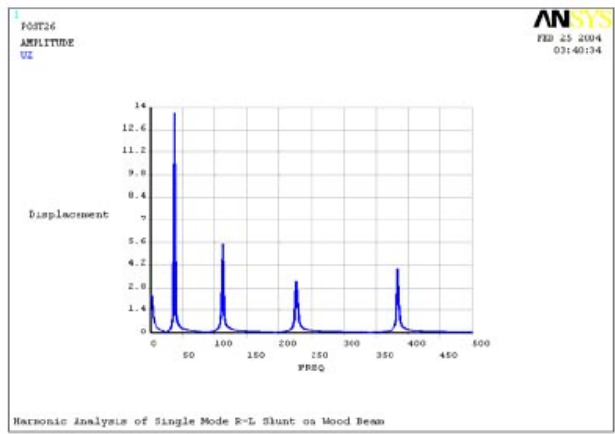

(c) Shunt $2^{\text {nd }}$ mode

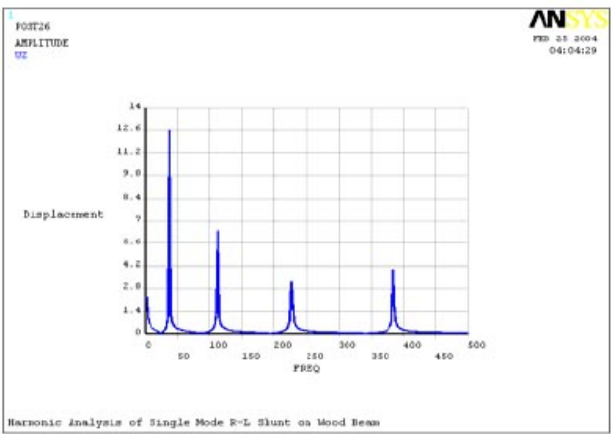

(b) Shunt $1^{\text {st }}$ mode

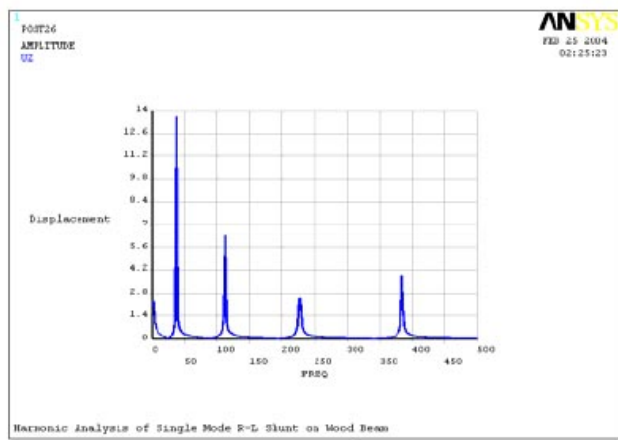

(d) Shunt $3^{\text {rd }}$ mode

FiguRE 7: Harmonic analysis of the wooden beam vibration 


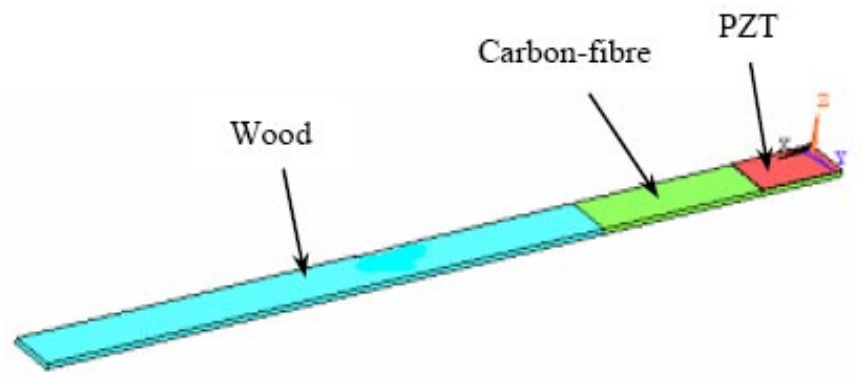

FIGURE 8: Built-up beam with PZT patch attached

Figure 7 displays the vibration spectrum of a wooden beam which Young's modulus is equal to $E_{b}=66 \mathrm{GPa}$, and density $\rho_{b}=553 \mathrm{Kg} / \mathrm{m}^{3}$. The results show that little amplitude has been reduced at natural frequencies. This is probably because the Young's modulus and the density of the wood are much smaller than that of the PZT ceramic.

\section{Built-up beam}

In order to improve the efficiency of vibration shunting for a wooden beam a built-up beam was constructed as shown in Figure 8. The left section is wooden material, right section is a composite material with Young's modulus $E_{b}=66 \mathrm{GPa}$, and density $\rho_{b}=1500 \mathrm{Kg} / \mathrm{m}^{3}$. The PZT patch was attached on the top of composite material beam.

Figure 9 is the simulation results of the built-up beam. It shows that the deduction of vibration amplitude at natural frequency is markedly improved. The first to third modes were reduced about $48 \%, 50 \%$, and $80 \%$ (or $5.68 \mathrm{~dB}$, $6 \mathrm{~dB}$, and $14 \mathrm{~dB}$ ) respectively. 


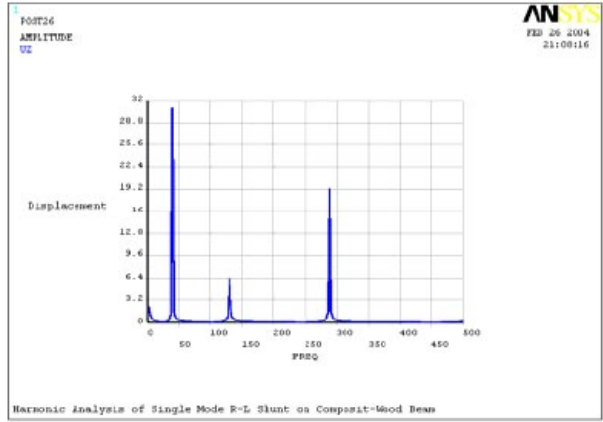

(a) Before Shunt

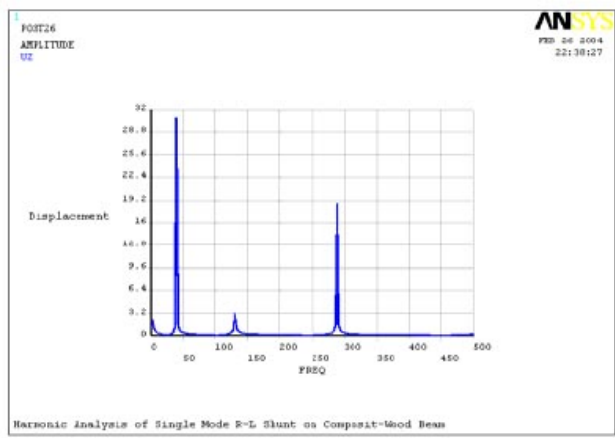

(c) Shunt $2^{\text {nd }}$ mode

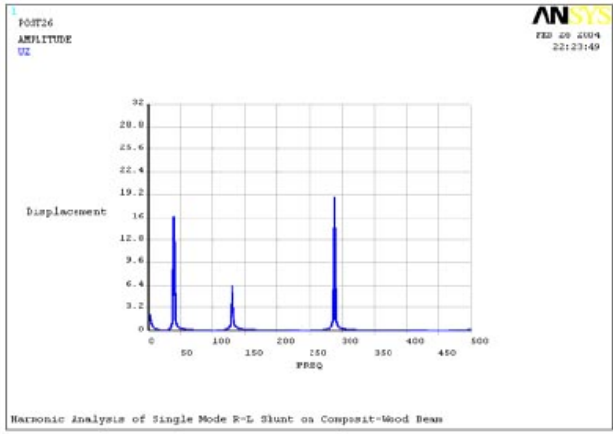

(b) Shunt $1^{\text {st }}$ mode

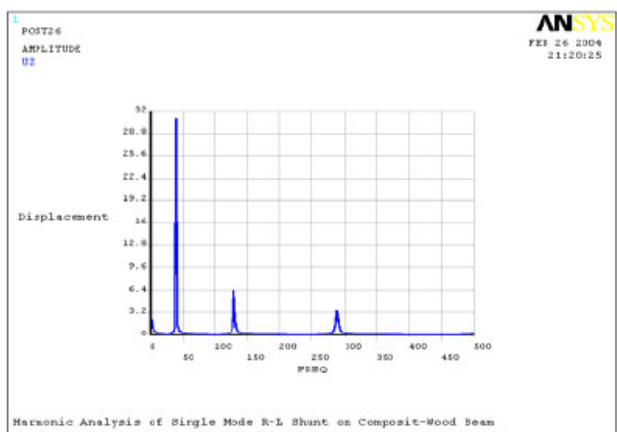

(d) Shunt $3^{\text {rd }}$ mode

Figure 9: Harmonic analysis of the built-up beam vibration 


\section{Experimental results}

The piezoelectric vibration shunt experiments were carried on aluminum, wood and carbon-fibre composite beams respectively. Figures 10-12 show the time and spectrum results of before and after shunting with the OROS spectrum analyzer. The beam lengths are about $500 \mathrm{~mm}$, widths are between $25-40 \mathrm{~mm}$, and thicknesses are between $2-3 \mathrm{~mm}$. The boundary conditions are free-clamped. The PZT used is PSI-5A4E piezoelectric sheet (T107-A4E602) from Piezo Systems. After the shunting process, the reduction in amplitude of vibration is $90 \%$ for the aluminum beam (Figure 10), $8 \%$ for wooden beam (Figure 11), and $80 \%$ for carbon-fibre composite beam (Figure 12). The experimental results were predicted by simulation. By using carbonfibre composite beam, the vibration reduction efficiency can be greatly improved when compared with the wooden beam since the Young's modulus of carbon-fibre composite beam can be chosen to be much closer to that of the PZT.

\section{Conclusions}

The use of piezoelectric materials in conjunction with resistor-inductor shunt circuits can effectively reduce the vibration amplitudes of structures. An analytical study on the parallel resistor-inductor piezoelectric shunt control using the Hamilton's principle and the Galerkin's method has been presented. The effectiveness of vibration reduction is related to the optimum size and placement of the piezoelectric transducer and the optimum value of resistors, and inductors. On the other hand, the experiments are costly and time consuming. It is thus desirable to have a system to be properly simulated before a final design can be made. This article shows a numerical method of designing a piezoelectric vibration shunt control system by using Finite Element Analyses. With the help of such numerical methods, designers can have much more flexibility in designing an optimal control system. Material properties 


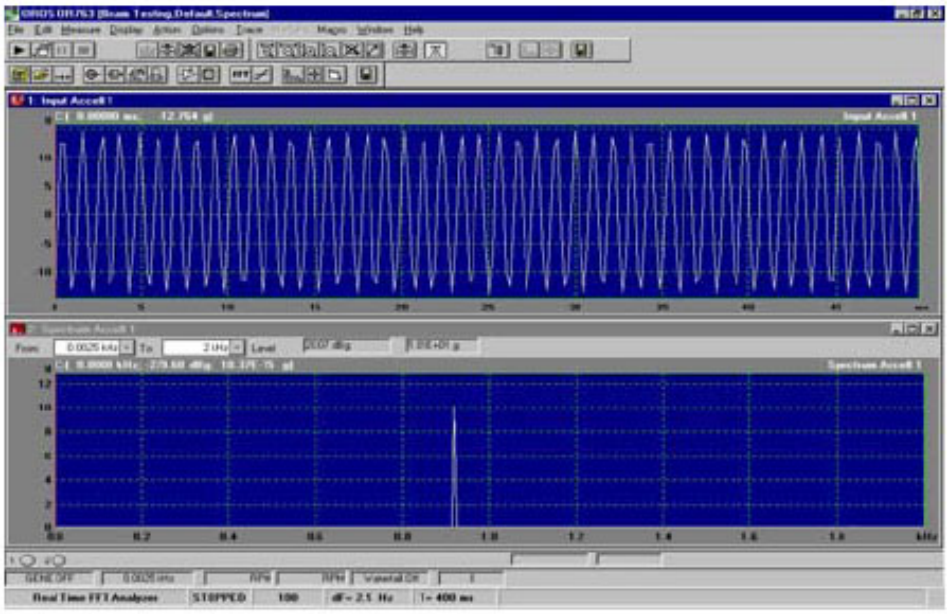

(a) Aluminum beam before shunting

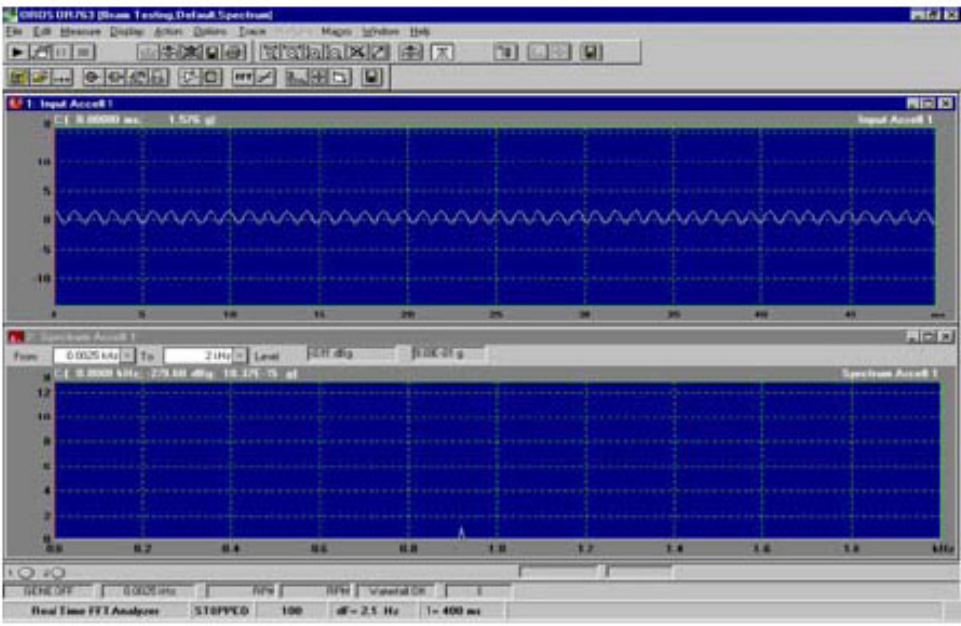

(b) Aluminum beam after shunting

FiguRE 10: 


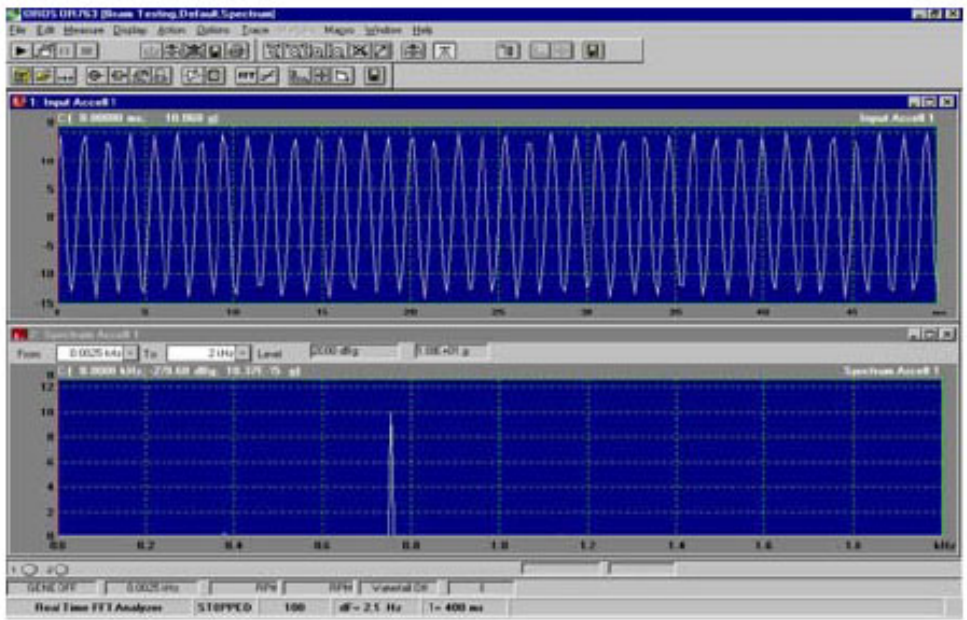

(a) Wooden beam before shunting

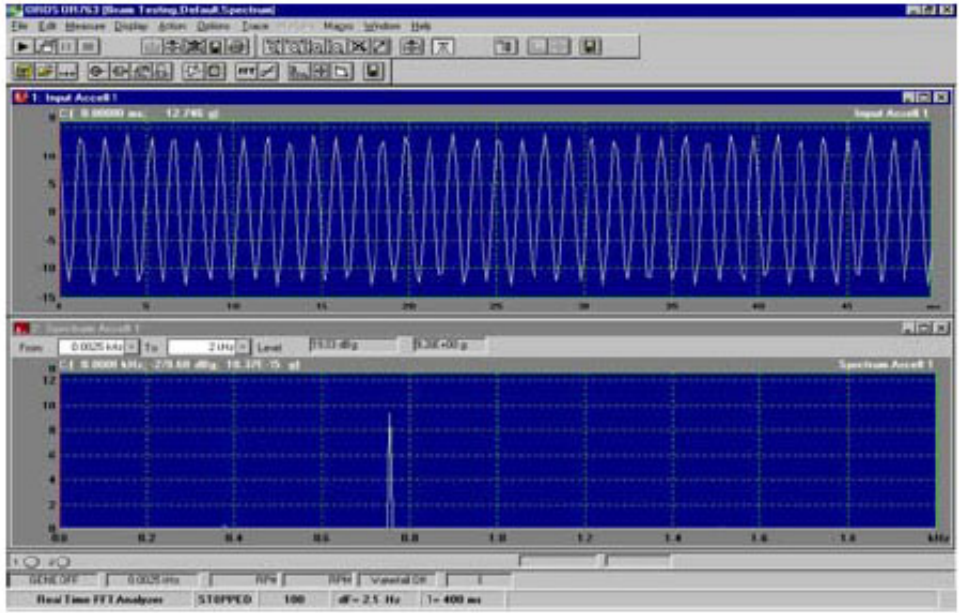

(b) Wooden beam after shunting

Figure 11: 


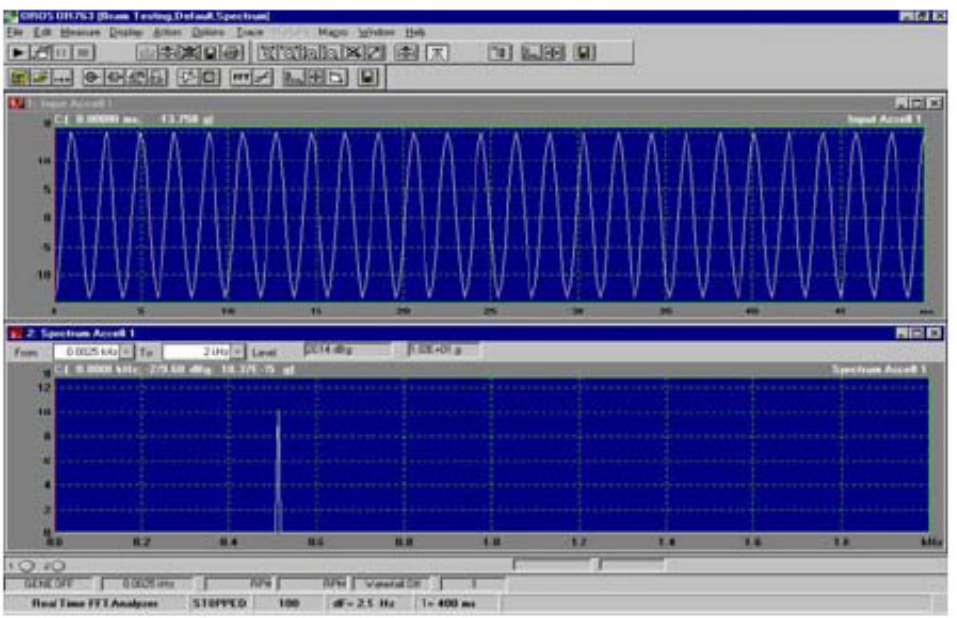

(a) Carbon-fibre composite beam before shunting

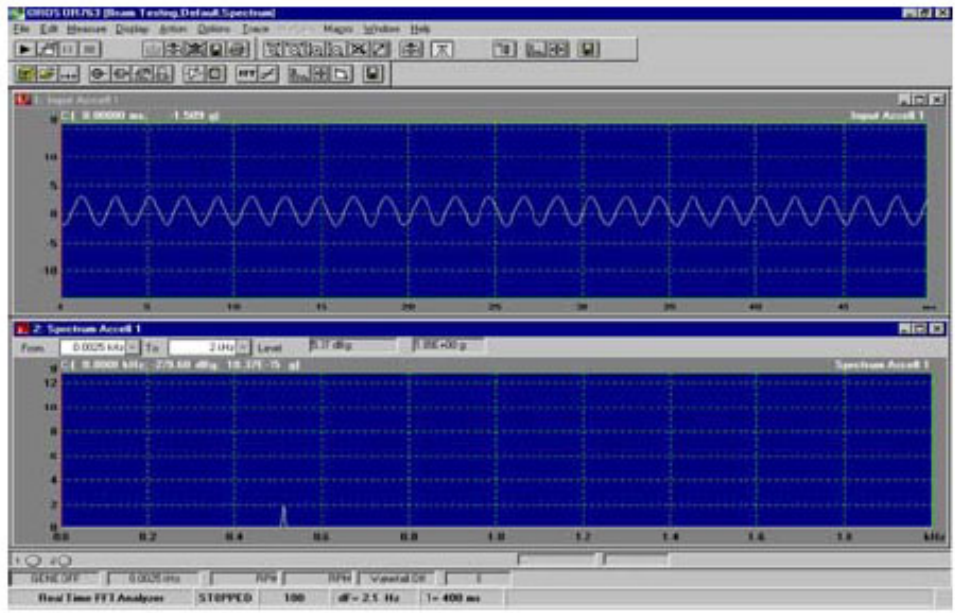

(b) Carbon-fibre composite beam after shunting

FIGURE 12: 
(Mechanical and physical) of the structure to be controlled can significantly affect the shunt control ability due to the neutral axis location. There is an optimal energy transfer ratio from the structure to the PZT for a given ratio of thickness between the structure and the PZT. The equation of the ratio of energy transfer has been derived. Simulation and experimental results have shown the impact of material property variations. Vibration control on the carbon-fibre beam, in particular, was shown to be very effective using this technique. The results are corroborated from analytical, experimental and computational analyses.

Acknowledgements: This work is co-supported by an Australian Research Council (ARC) grant (Grant number LP0222482).

\section{References}

[1] D. L. Edberg, A. S. Bicos, C. M. Fuller, J. J. Tracy and J. S. Fechter, Theoretical and Experiment Studies of a Truss Incorporating Active Members, J. Intell. Mater. Syst. and Struct., Vol. 3, p. 444, 1992. C734

[2] A. J. Fleming, S. Behrens and S. O. R. Moheimani, Reducing the Inductance Requirements of Piezoelectric Shunt Damping Systems, Smart Mater. Struct., Vol. 12, pp. 57-64, 2003. C734

[3] N. W. Hagood and A. von Flotow, Damping of Structural Vibrations with Piezoelectric Materials and Passive Electrical Networks, Journal of Sound and Vibration, 146(2), pp. 243-268, 1991. C734

[4] J. J. Hollkamp, Multimodal Passive Vibration Suppression with Piezoelectric Materials and Resonant Shunts, J. Intell. Material Syst. Structures, Vol. 5, January 1994. C734 
[5] S. Y. Wu, Piezoelectric Shunts with a Parallel R-L Circuit for Structural Damping and Vibration Control, Proceedings of the International Society for Optical Engineering, Vol. 2720, pp. 259-269, 1996. C734 